far EAQUA has achieved its mission of enhancing growth of the Quaternary science community in the region through training, collaborative research and information exchange. Participants were urged to come up with tangible results, such as student exchange programs and joint proposals. He challenged the Institute of Marine Sciences of the University of Dar es Salaam to develop a postgraduate program in maritime archeology, which could boost archeological studies in the entire Great Lakes Region.

The EAQUA workshop was preceded by a one day INQUA/EAQUA meeting with presentations from INQUA, Pan African START Secretariat (PASS) and EAQUA country representatives. INQUA presented objectives, activities and available opportunities for the EAQUA members to participate in the programs of the commissions. PASS presented opportunities to the members for training and research, for example, the African Climate Change Fellowship Program (ACCFP) and the Educa- tion Program on Climate Change and Biodiversity Conservation. Participants were urged to take a leading role in utilizing these opportunities. Country representatives reported on Quaternary research activities in the region and felt that more capacity building is required.

The general theme of the $3^{\text {rd }}$ EAQUA workshop was "On- and off-shore: Eastern Africa during the last $100 \mathrm{ka".}$ The workshop had 40 oral and 5 poster presentations. Talks were divided into six sessions namely (i) Marine and lacustrine records and reconstruction, (ii) Techniques and methodological development in Quaternary research, (iii) Paleoclimate reconstruction, (iv) Vegetation reconstruction (v) Recent trends in climate change-Impacts and vulnerability assessment for eastern Africa, and (vi) Trade, anthropology and archeological studies in Eastern Africa. Time was also allocated for a roundtable discussion where several priority areas of research were identified: (i) Compilation of modern archives of climatic re- cords for the last millennia, (ii) Reconnaissance program to establish caves hosting speleothems, (iii) Creation of a database of Quaternary scientists and projects working in eastern Africa; (iv) Archeology, environment and Humans focusing on issues such as hydrology, vegetation, fire, human-climatic influences, and others. Additionally, the need for several focused meetings with a progressive agenda was emphasized.

The EAQUA workshop concluded with a discussion of association matters, including the election of executive members. Elected for a period of 2 years are: Prof. Mohammed Umer (President), Prof. Alfred N.N. Muzuka (Vice President), Ms Christine Ogolla (Secretary General), Ms Jackline Nyiracyiza (Treasurer), Prof. Asfawossen Asrat (News Letter Editor), Dr. Immaculate Ssemmanda (National Representative (NR Uganda), Ms. Rahab Kinyanjui (NR Kenya), Elgidius Ichumbaki (NR Tanzania), Dr. Julius Lejju (Ex-Officio), Dr. Margareth Avery (INQUA).

\title{
Multidecadal and centennial ENSO variability
}

\section{San Diego, USA, 3-4 September 2010}

\author{
Jorge Sánchez-Sesma ${ }^{1}$ and Arthur Miller ${ }^{2}$ \\ 'Mexican Institute of Water Technology, Jiutepec, Mexico; jsanchez@tlaloc.imta.mx \\ ${ }^{2}$ Scripps Institution of Oceanography, University of California, San Diego, USA
}

ENSO is the largest signal of sub-annual climate variability in the Pacific Ocean, affecting not only coastal but also inland locations. Its torrential rains and severe droughts result in economical losses of several hundred millions of dollars in affected countries, from the USA and Mexico to southern South America and as far as Australia. The increase of ENSO frequency and intensities during the second part of the $20^{\text {th }}$ century has affected various sectors, from agriculture to health, from fisheries to the economy. Thus understanding, and ultimately forecasting ENSO variability, has an enormous potential societal benefit.

Although ENSO knowledge has been expanding enormously during last few years, scientists have not yet developed joint and interdisciplinary efforts to better reconstruct and model multidecadal and centennial climate variability (MCEV). The long-term trends that have been reconstructed through numerous proxy variables have neither been analyzed nor modeled well enough to understand the mechanisms required for long-term forecasts. The present trend towards more

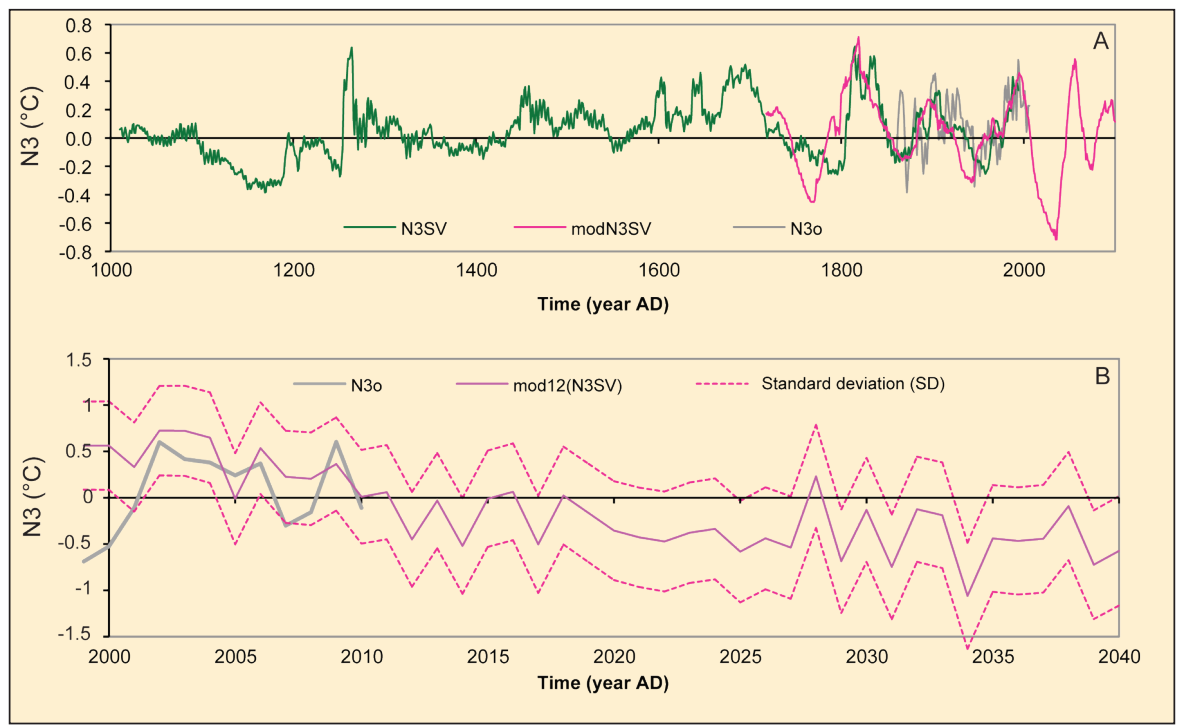

Figure 1: Comparison of three ENSO (N3 annual average) models. A) 21-year moving average smoothed series. The green line (N3s) is the 1000-1999 AD Zebiak-Cane (ZC) model by Mann et al. (2005). The pink line (N3SV) was obtained from an ensemble's average of ZC simulation forced by volcanic and solar activity. The gray line (N3o) represents smoothed observation data for the last 150 years. B) Zoom of the annual (non-smoothed) N3SV same model, as A), over 2000-2040 AD and validation with independent observational data. Figure adapted from Sánchez-Sesma (2010).

La Niña events, with more rainfall and tropical cyclones (as 2010 showed us) is highlighting the need to take into account different aspects of ENSO (such as multidecadal trends or ocean-atmosphere interactions) and merge the knowledge from proxy reconstructions, physical and mathematical simulations, non-linear climate analyses and socio-economical research to better understand, predict, and 
mitigate potential ENSO climate impacts in the future (see e.g., Fig. 1).

In order to discuss all these aspects, an international workshop on MCEV focusing on analysis, reconstruction and simulation of ENSO related climate oscillations was held in San Diego. The workshop drew more than 20 experts from Australia, Canada, Mexico, Spain, UK and the USA. The participants were mainly researchers from the fields of climate simulations and reconstructions or working on climate impacts and their related economical aspects. This workshop was a complementary meeting to the $10^{\text {th }}$ International Conference on Paleoceanography $\left(10^{\text {th }} I C P\right)$ and was sponsored by the Institute for Mexico and the United States (UC-MEXUS) of the University of California.

Introductory presentations covered a wide range of topics including ENSO modeling, the linear and non-linear trends of climate variability, the differences between local and remote processes, the inherent noise behind the records and their biological feedbacks, GCM projections for the Pacific Decadal Oscillation in the $21^{\text {st }}$ century, ENSO and PDO coincident contributions and trends, and new highresolution geochemistry proxy records. Other aspects also discussed included: MCEV from simulations and proxies, nonlinear decomposition of ENSO simulated records, and orbitally induced mean states of climate change in the Tropical Pacific during interglacials. Emphasis on ENSO climate reconstructions from geological records was provided through an overview of different aspects: (a) on the most adequate archives and the sensitivity of proxy variables linked to ENSO conditions, (b) on the influence of hemispheric climate processes on sea surface temperature (SST) during the Holocene, and (c) on isotopic and geochemical analyses from sedimentary records to determine the transmission of the ENSO signal from the western tropical Pacific and the relationship between ENSO and the California Current variability over the past millennium.

Another session focused on nonlinear mathematical analyses. For example, modeling the millennial synchronization between Greenland and Antarctic $\delta^{18} \mathrm{O}$ records and the non-linear behavior of ENSO on different timescales were discussed.
The concluding session was centered around the regional impacts of ENSO: analysis of inter-annual variability of precipitation and temperatures over Mexico, the social value of climate predictions in terms of public investments, and the reliance on information provided by institutions and organizations.

The next workshops will focus on centennial scale climate forcings (volcanic and solar). Reconstructions, models and their centennial scale forecasts will be discussed taking into account the associated global and regional climate variability.

\section{References}

Emile-Geay, J., Cane, M., Seager, R., Kaplan, A. and Almasi, P., 2008: El Niño as a mediator of the solar influence on climate, Paleoceanography, 22(3), doi: 10.1029/ 2006PA001304.

Loutre, M.F., Berger, A., Bretagnon, P. and Blanc, P.-L., 1992: Astronomical frequencies for climate research at the decadal to century time scale, Climate Dynamics, 7: 181-194.

Mann, M.E., Cane, M.A., Zebiak, S.E. and Clement, A., 2005: Volcanic and Solar Forcing of The Tropical Pacific Over the Past 1000 Years, Journal of Climate, 18: 447-456.

Sánchez-Sesma, J., 2010: Multi-centennial scale analysis and synthesis of an ensemble mean response of ENSO to solar and volcanic forcings, Climate of the Past Discussions, 6: 2055-2069.

Rein, B., Lückge, A., Reinhardt, L., Sirocko, F., Wolf, A. and Dullo, W.-C., 2005: El Niño variability off Peru during the last 20,000 years, Paleoceanography, 20: doi: 10.1029/2004PA001099.

\title{
Linking monsoon systems across timescales
}

\section{$2^{\text {nd }}$ PAGES Global Monsoon Symposium, Shanghai, China, 13-15 September 2010}

\author{
Pinxian Wang ${ }^{1}$, B. WAng ${ }^{2}$, And T. Kiefer ${ }^{3}$ \\ 'State Key Laboratory of Marine Geology, Tongji University, China; pxwang@online.sh.cn \\ ${ }^{2}$ School of Ocean and Earth Science and Technology, University of Hawaii, Honolulu, USA; ${ }^{3}$ PAGES International Project Office, Bern, Switzerland
}

Monsoon systems have earned increasing attention from the climatology community over the past decades, yet remain a subject of regional, if not local studies. Following the first Global Monsoon (GM) meeting in 2008 (see report in PAGES news $17(2), 2009)$, a second meeting was held in an attempt to put regional monsoons into the context of a global system, and to analyze their variations across a range of timescales. A total of 95 participants from 12 countries presented 30 talks and 39 posters.

One focus was the hydrological cycle. In present-day climate, the GM was shown to be coordinated by internal feedback processes such as ENSO variability. An increasing trend in global monsoon precipitation over the last 30 years is attributed to both the effects of global warming and atmosphere-ocean interaction in the Pacific Ocean (B. Wang). However, the link between SST and precipitation is not straightforward (J. Fasullo). In his keynote,

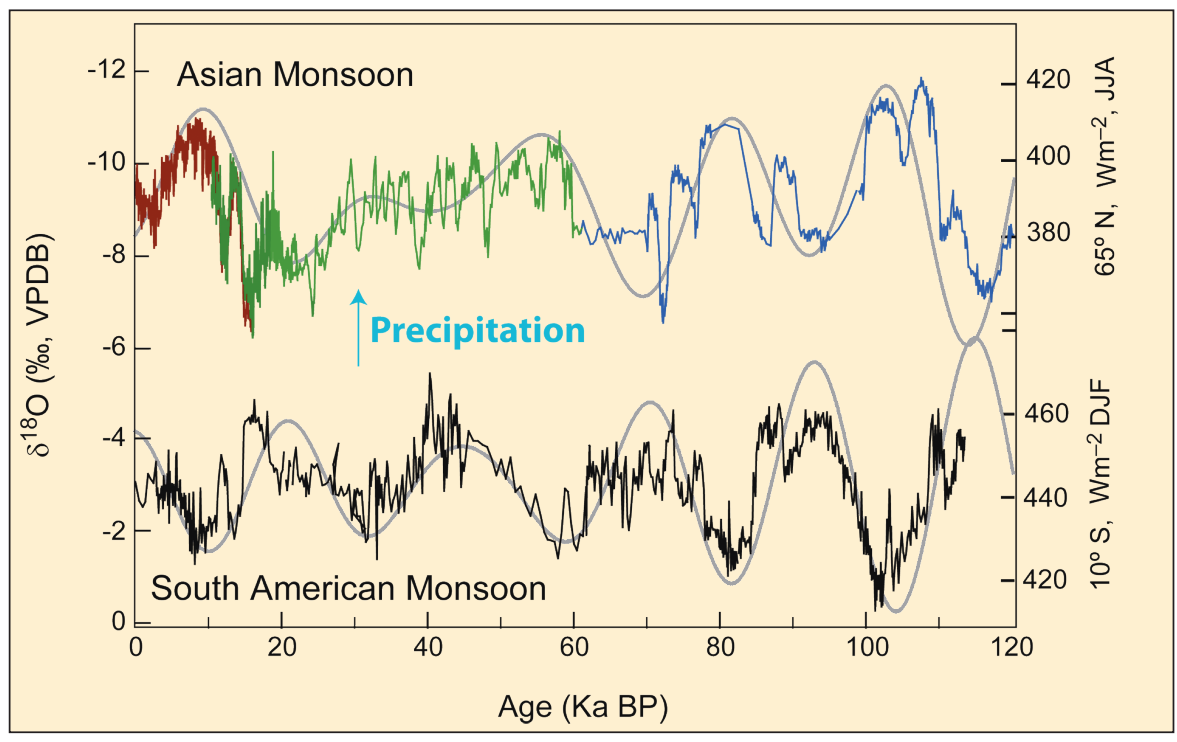

Figure 1: Interhemispheric comparison of changes in monsoon precipitation and summer insolation between eastern Asia and South America. Precipitation changes are reflected in $\delta^{18} \mathrm{O}$ records of speleothem calcite from Dongge cave (brown; Dykoski et al., 2005), Hulu cave (green; Wang et al., 2001), and Sanbao cave (blue; Wang et al., 2008) from eastern China, and from Botuverá cave in southern Brazil (black; Cruz et al., 2005). Insolation data are from (Berger, 1978). Figure courtesy of Hai Cheng.

Peter Webster showed that the area of the (using a fixed criterion of $28^{\circ} \mathrm{C}$ ) increased SST-defined Tropical Ocean Warm Pool by $70 \%$ since 1920 and is expected to oc- 